\title{
Duodenal mucosal damage in 31 infants with gastroenteritis
}

\author{
G. L. BARNES and R. R. W. TOWNLEY \\ From the Department of Gastroenterology, Royal Children's Hospital, Melbourne, Australia
}

\begin{abstract}
Barnes, G. L., and Townley, R. R. W. (1973). Archives of Disease in Childhood, 48, 343. Duodenal mucosal damage in 31 infants with gastroenteritis. Duodenal biopsies taken in the acute stage of gastroenteritis in 31 infants have shown histological abnormality and disaccharidase depression in the majority. In 5, mucosal damage was severe with changes similar to those seen in coeliac disease. Repeat biopsies in 3 of these showed marked improvement after 3 days, 8 days, and 7 weeks, respectively. Persisting sugar intolerance occurred in approximately $50 \%$ of patients under 6 months of age, but this complication bore no relation to disaccharidase depression in the acute stage of the illness.
\end{abstract}

Few reports have been published of the findings in duodenal mucosa in gastroenteritis and those available give conflicting results. Some suggest that there is no significant histological abnormality (Rosensweig, Dawkins, and Bayless, 1967; Hirschhorn and Molla, 1969) but others (Toccalino et al., 1971) report definite change.

Sporadic duodenal biopsies performed in the past in children with gastroenteritis in this hospital have sometimes shown flattening of villi and infiltration of the lamina propria with inflammatory cells.

These considerations prompted us to examine a group of infants with gastroenteritis, utilizing duodenal biopsy to examine histological damage and disaccharidase depression.

Clinical follow-up was undertaken to assess any relation between disaccharidase depression in the acute stage of the illness and persisting sugar intolerance.

The working hypotheses for the study were (1) considerable damage to the duodenal mucosa can occur in infantile gastroenteritis; (2) persisting sugar intolerance is related to the degree of damage.

\section{Material and methods}

Gastroenteritis was defined as a febrile illness of less than 10 days' duration associated with diarrhoea and vomiting where there was no other evident cause for the symptoms.

For this study a selection was made of 49 consecutive admissions to the Royal Children's Hospital: the infants

Received 19 September 1972. were less than 12 months of age and had a provisional diagnosis of gastroenteritis.

The parents were interviewed and the intended investigations explained in detail. It was pointed out that this was a research project with the aim of increasing understanding of the causes of gastroenteritis in the hope that a more rational approach to treatment might be found. We explained that in our experience duodenal biopsy was a safe procedure, and told them of the one complication which had been seen here since the introduction of the present capsule (see below). The possibilities of perforation and bleeding were mentioned. The use of fluoroscopy was discussed, explaining that the radiation dose was equivalent to one chest $x$-ray. We also suggested that in a few of the children investigated some information might be obtained of direct benefit to the child, e.g. giardia infection. We also believed at the time that disaccharidase depression would indicate those infants requiring a lactose-free formula.

Almost all parents were agreeable to these investigations and only 3 of the 49 infants were excluded due to parental misgivings.

Although there is no evidence that the risks of the procedure are greater in very small infants, the experience of this unit includes less than 20 biopsies in infants under $4.0 \mathrm{~kg}$ and we felt it advisable to exclude a group of 8 such patients.

We are, however, convinced of the safety of this procedure in infants over $4.0 \mathrm{~kg}$. Since the introduction of the capsule currently used in this department, over 1500 duodenal biopsies have been performed, many in infants under 6 months of age. There has been one complication. An infant of 14 months developed melaena which settled with conservative management. As performed in this unit, the procedure takes approximately between 5 and 15 minutes. It is usually done on an outpatient basis. 
Of the remaining 38 infants 7 were later excluded having not fulfilled the criteria for a diagnosis of gastroenteritis (1 Giardia lamblia infection, 1 severe malnutrition, 1 feeding problem, 3 with prolonged antecedent sugar intolerance, and 1 with an obscure fatal metabolic disturbance).

This left 31 infants with gastroenteritis who weighed more than $4.0 \mathrm{~kg}$. Each of these had a duodenal biopsy performed after rehydration and within $\mathbf{4 8}$ hours of admission.

Males outnumbered females $21: 10.10$ infants were under 6 months of age. The length of history of the illness was less than 2 days in 8 cases, 2 to 7 days in 22 , and more than 7 days in one. 12 infants required intravenous therapy. 3 had concurrent upper respiratory tract infection and 1 had a persistent ductus arteriosus.

All patients were given $5 \mathrm{mg}$ vitamin $\mathrm{K}$ by intramuscular injection the day before biopsy. Oral feeds were $5 \%$ glucose solution for the 8 hours before the test. Premedication included 1 to $3 \mathrm{mg}$ metoclopramide syrup (Maxolon) plus quinalbarbitone $50 \mathrm{mg}$ in the older infants. Swabs for culture were taken from throat and faeces. A sterile radio-opaque rubber tube was used to sample gastric and duodenal contents. Samples were cultured for bacteria, yeasts, and, in the first 10 cases, viruses. Culture methods and detailed results are the subjects of a further publication (Bishop, Barnes and Townley, in preparation).

A Watson paediatric biopsy capsule with a $2 \mathrm{~mm}$ port, mounted on Kifa $x$-ray opaque tubing, was used. The capsule was placed in the 4th part of the duodenum within 2 to $3 \mathrm{~cm}$ of the ligament of Treitz using fluoroscopic control. The radiation dose was comparable to that required for a chest $x$-ray. Biopsy specimens were divided into 2 pieces. One portion was fixed in Bouin's solution and stained with haematoxylin and eosin. Assessment of histological changes was made by one of us (R.R.W.T.) without knowledge of the clinical situation. Specimens were graded as showing normal appearance, mild, moderate, or severe change as described by Townley, Khaw, and Shwachman (1965) and as illustrated in Fig. 1. The second portion was stored in Parafilm at $-20^{\circ} \mathrm{C}$ and used for disac-

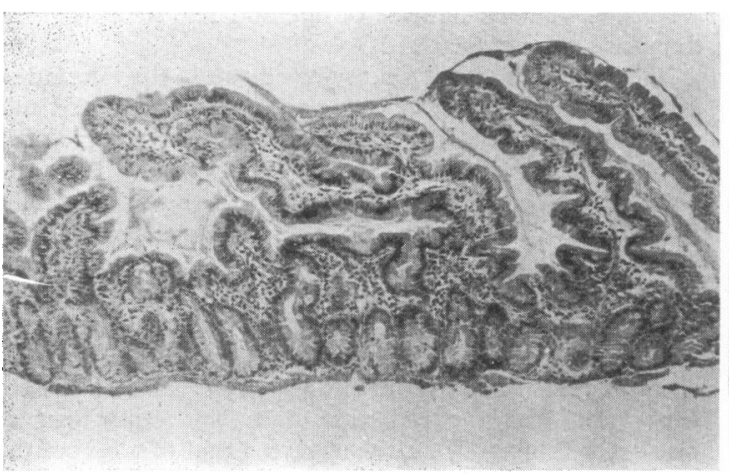

(a)

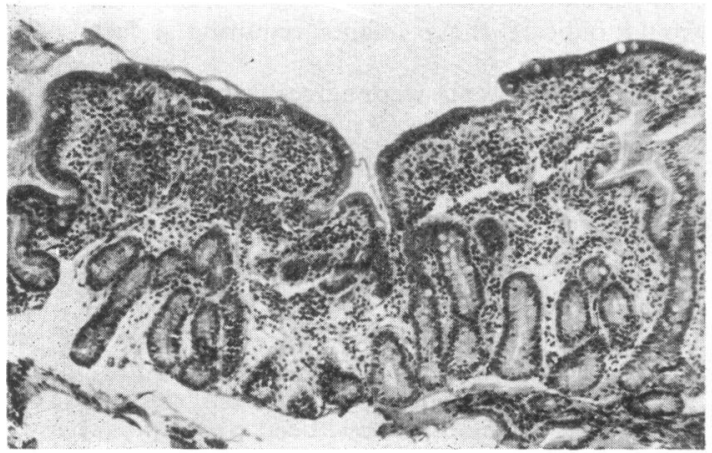

(c)

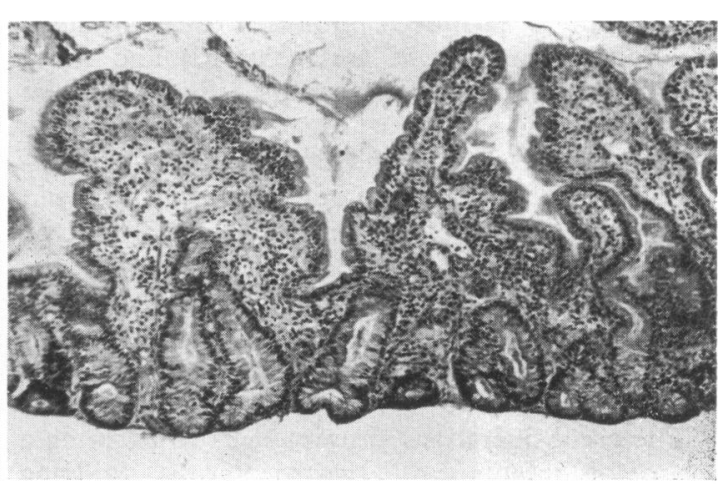

(b)

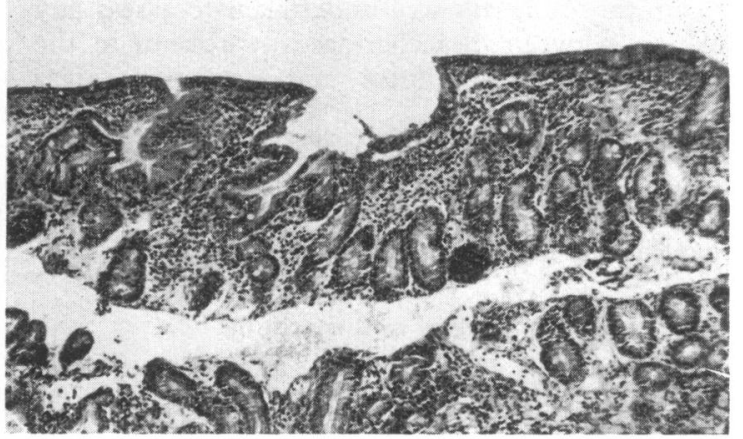

(d)

FIG. 1.-Grading of histological damage: $(a)$ normal $(\times 86) ;.(b)$ mild change showing widening of villi, mild cellular infiltration of the lamina propria, and early epithelial damage $(\times 86) ;.(c)$ moderate change with considerable blunting of villi, obvious cellular infiltration, and epithelial damage $(\times 86) ;.(d)$ severe change with complete villous flattening, heavy cellular infiltration and severe epithelial change $(\times 86$.). 
charidase assay within 1 to 10 days by a modification of the method of Dahlqvist (1964).

Normal disaccharidase levels in childhood have not been reported in adequate numbers in the literature to allow valid comparison with our results. For the purposes of this study 'normal' levels were defined from a consecutive series of 100 children investigated in this department for diarrhoea or failure to thrive, who had normal histology and in whom no organic disease was revealed. The levels are therefore likely to be lower than true normal. The incidence of disaccharidase depression in the present study may thus be underestimated. Lower limits of 'normal' were accepted as follows in units/g wet wt: maltase 9.0, sucrase $3 \cdot 5$, isomaltase $2 \cdot 5$, lactase $1 \cdot 0$. Each of these levels is at or below the 5 th centile (Fig. 2). Calculation of disaccharidase activity per $\mathbf{g}$ protein made no significant difference to results. (1 unit disaccharidase activity hydrolyses $1 \mu \mathrm{mol}$ disaccharide/minute at $37^{\circ} \mathrm{C}$.)

All children in the study were given a cow's milk formula within 1 to 3 days of admission. Stools were tested for reducing substances according to the method described by Kerry and Anderson (1964). Two Clinitest positive stools after reintroduction of cow's milk formula were taken as the indication for a lactosefree formula (Glucose-Nutramigen). After 1 week a further challenge with cow's milk was made. If a child showed two Clinitest positive stools at this stage he was regarded as having persisting sugar intolerance.

Three infants showing severe changes in the duodenal sections had a second biopsy 3 days, 8 days, and 7 weeks later, respectively.

\section{Results}

Cultures. From only one infant was a recognized pathogen isolated. This was Salmonella typhimurium found in the faeces of a 9-month-old infant. Esch. coli was grown from gastric or duodenal juice in 12 cases but none was enteropathogenic to serological testing. Candida sp. were found in stomach and duodenum in 12 infants, and in faeces only in 4 others. Virus studies were unrewarding.

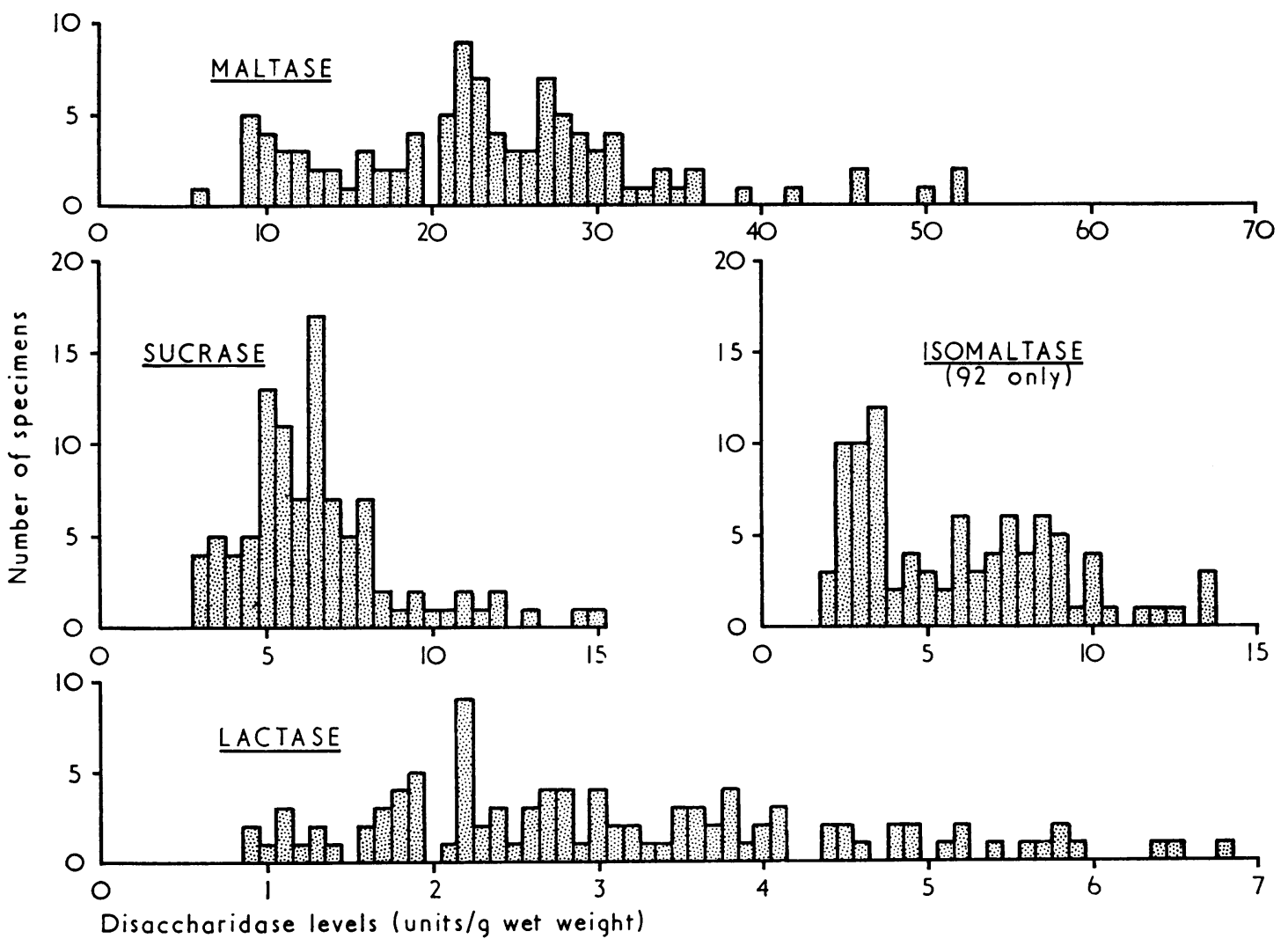

FIG. 2.-Disaccharidase levels in 100 children with diarrhoea or failure to thrive who had normal duodenal histology and in whom no organic disease was revealed. (1 unit of disaccharidase activity hydrolyses 1 umol disaccharide $/ \min$ at $37^{\circ} \mathrm{C}$.) 
Duodenal biopsies. Of the 31 biopsies only 5 were interpreted as histologically normal. 5 showed severe changes similar to those seen in coeliac disease. The remaining 21 showed mild (11) or moderate (10) abnormality. The changes included villous flattening, replacement of normal columnar epithelium with cuboidal cells, and infiltration of the lamina propria with inflammatory cells, the majority of which were plasma cells. Epithelial changes tended to be patchy.

Generalized disaccharidase depression or lactase depression alone was seen in 16 cases. As would be anticipated, disaccharidase depression was associated with the more severe histological damage (Table I).

TABLE I

Duodenal histology and disaccharidase depression (generalized or lactase alone)

\begin{tabular}{l|c|c|c|c}
\hline & $\begin{array}{c}\text { Normal } \\
\text { histology }\end{array}$ & $\begin{array}{c}\text { Mild } \\
\text { change }\end{array}$ & $\begin{array}{c}\text { Moderate } \\
\text { change }\end{array}$ & $\begin{array}{c}\text { Severe } \\
\text { change }\end{array}$ \\
\hline $\begin{array}{l}\text { Disaccharidase } \\
\text { depression }\end{array}$ & 1 & 2 & 8 & 5 \\
$\begin{array}{l}\text { Disaccharidases normal } \\
4\end{array}$ & 9 & 2 & 0 \\
\hline
\end{tabular}

Of the 5 children whose biopsies showed severe changes, 3 had a further biopsy performed. In each case histology and disaccharidase levels indicated a rapid return towards normal (Fig. 3, Table II).

The degree of mucosal damage was not related to clinical severity of the disease. 6 of the 12 infants requiring intravenous therapy showed disaccharidase depression, compared with 10 of the other 19. Histology was normal in 2 and showed severe change in 2 of the intravenous therapy group compared with 3 normal and 3 severe of the rest.

Sugar intolerance. Clinical follow-up has shown that persisting sugar intolerance is not related to disaccharidase depression in the acute stage of the illness (Table III), but appears to be related to age. 5 of 10 infants under 6 months of age showed persisting sugar intolerance, as previously defined, compared with 2 of 21 infants aged 6 to 12 months. These proportions are maintained when the 8 infants under $4.0 \mathrm{~kg}$, who did not have a biopsy, are included, i.e. 9 of 17 under 6 months versus 2 of 22 infants of 6 to 12 months.

TABLE III

Acute disaccharidase depression and persisting sugar intolerance

\begin{tabular}{l|c|c}
\hline & No. & $\begin{array}{c}\text { Persisting } \\
\text { sugar } \\
\text { intolerance }\end{array}$ \\
\hline $\begin{array}{l}\text { Disaccharidase depression } \\
\text { (generalized or lactase only) } \\
\text { Disaccharidases normal }\end{array}$ & 16 & 3 \\
\hline
\end{tabular}

\section{Discussion}

There are few publications describing the state of the duodenal mucosa in gastroenteritis. This is especially so in childhood where there have been doubts about the safety of the procedure (Partin and Schubert, 1966).

Rosensweig et al. (1967) found minimal change in proximal jejunal biopsies at the height of the illness

TABLE II

Disaccharidase levels in 3 children who had 2 duodenal biopsies each

\begin{tabular}{|c|c|c|c|c|c|c|c|}
\hline \multirow{2}{*}{$\underset{\text { (mth) }}{\text { Age }}$} & \multirow{2}{*}{$\begin{array}{l}\text { Interval } \\
\text { between } \\
\text { biopsies }\end{array}$} & \multicolumn{2}{|c|}{ Histological change } & \multicolumn{4}{|c|}{ Disaccharidases (units/g wet wt) } \\
\hline & & Initial & Repeat & Ini & tial & & peat \\
\hline 7 & 7 wk & $\begin{array}{l}\text { Severe } \\
\text { Severe }\end{array}$ & $\begin{array}{l}\text { Mild } \\
\text { Mild } \\
\text { Normal }\end{array}$ & $\begin{array}{l}\text { Maltase } \\
\text { Sucrase } \\
\text { Isomaltase } \\
\text { Lactase } \\
\text { Maltase } \\
\text { Sucrase } \\
\text { Isomaltase } \\
\text { Lactase } \\
\text { Maltase } \\
\text { Sucrase } \\
\text { Isomaltase } \\
\text { Lactase }\end{array}$ & $\begin{array}{l}7 \cdot 7(51 \cdot 6) \\
2 \cdot 1(14 \cdot 2) \\
2 \cdot 3(15 \cdot 1) \\
1 \cdot 6(10 \cdot 5) \\
2 \cdot 7(28 \cdot 2) \\
0.9(9 \cdot 7) \\
0.5(4 \cdot 9) \\
0 \cdot 2(1 \cdot 6) \\
8 \cdot 6(50 \cdot 2) \\
1 \cdot 7(9 \cdot 9) \\
2 \cdot 1(12 \cdot 2) \\
1 \cdot 1(6 \cdot 5)\end{array}$ & $\begin{array}{r}19 \cdot 5 \\
4 \cdot 2 \\
6 \cdot 4 \\
5 \cdot 7 \\
26 \cdot 0 \\
6 \cdot 9 \\
7 \cdot 7 \\
4 \cdot 4 \\
41 \cdot 9 \\
12 \cdot 2 \\
8 \cdot 3 \\
4 \cdot 2\end{array}$ & $\begin{array}{c}(137 \cdot 5) \\
(30 \cdot 0) \\
(45 \cdot 1) \\
(40 \cdot 2) \\
\text { (not done) } \\
\text { (not done) } \\
\text { (not done) } \\
\text { (not done) } \\
(274 \cdot 9) \\
(80 \cdot 2) \\
(54 \cdot 3) \\
(27 \cdot 5)\end{array}$ \\
\hline
\end{tabular}

Figures in brackets units/g protein. 


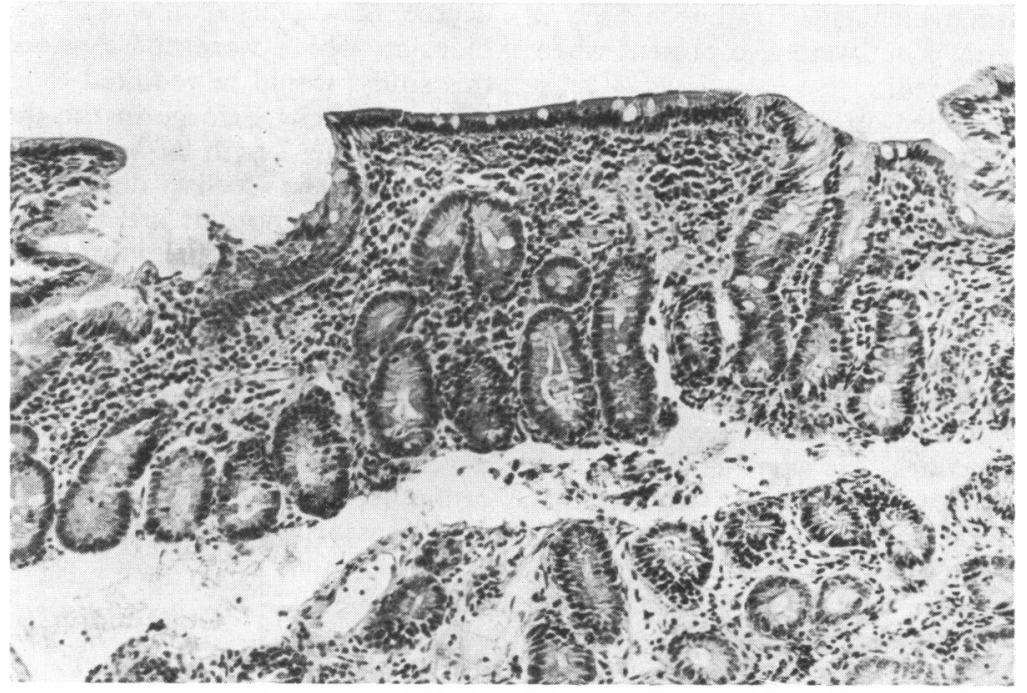

(a)

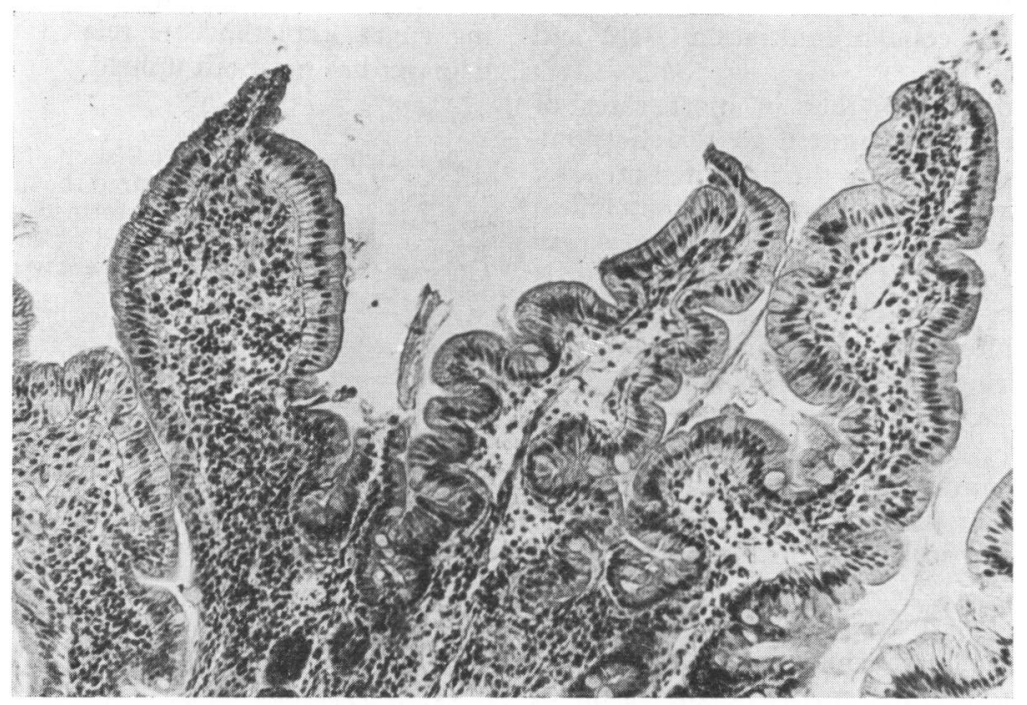

(b)

FIG. 3.-(a) Severe histological change in a 9-month-old infant (same specimen as Fig. 1d) ( $\times 150$.$) ; (b) mild change in the$ same infant 8 days later $(\times 150$.$) .$

and in the convalescent stage in 3 prison volunteers with typhoid fever. Disaccharidase levels remained normal throughout. In cholera, rapid serial changes in disaccharidase activity were noted within a few days by Hirschhorn and Molla (1969), though there was no change histologically. The brush border remained normal to electron microscopy.
Children with acute diarrhoea had biopsies taken by Toccalino et al. (1971) between the 5th and 10th day after admission to hospital. The majority showed decreased height and width of villi, epithelial change, decreased number of goblet cells, and infiltration of the lamina propria by lymphocytes, plasma cells, and occasional polymorphonuclear leucocytes. These changes were especially promi- 
nent in cases from which enteropathogenic Esch. coli (EEC) were grown but were also present when no pathogen was isolated.

Two infants included in a series of cases of lactose intolerance described by Burke, Kerry, and Anderson (1965) appeared to have initially suffered a gastroenteritis-like illness. Duodenal biopsies showed changes similar to those in our cases, but the investigations were performed some months after the illness.

Several necropsy studies have been reported. Bray in 1945 described infants who died from Esch. coli and found very little evidence of inflammation of the intestine. He concluded that the term 'gastroenteritis' was incorrect. Other publications described varying degrees of damage (Rho and Josephson, 1967; Handforth and Sorger, 1961).

Animal studies also reveal differing changes. Experimental $S$. typhimurium infection in rats resulted in no change in stomach and upper small bowel in most (Maenza et al., 1970). However, pigs with transmissible gastroenteritis, a viral infection of the upper small bowel, showed severe villous atrophy and cellular infiltration (Bohl and Cross, 1971).

Our own study shows that in most cases of infantile gastroenteritis admitted to this hospital, there is significant damage to the intestinal mucosa. The degree of damage is not related to the clinical severity of the illness. Histological changes may be confused with those of coeliac disease, and it is likely that some cases of 'coeliac disease' who responded to gluten-free diet in the past were children recovering from gastroenteritis. The gastrointestinal tract can respond to injury in only a limited number of ways. Collins (1965) lists more than 50 clinical and experimental situations in which small intestinal mucosal damage with villous atrophy has been seen, including 1 case of gastroenteritis.

Walker-Smith (1970) described transient gluten intolerance in a child after salmonella gastroenteritis, suggesting that this entity might be the result of transient depression of dipeptidase activity. Histology showed considerable villous flattening and cellular infiltration in his patient. Biopsy was normal 1 year later.

Our own study indicates that mucosal recovery appears to be rapid. Histology and disaccharidase levels returned almost to normal in the 3 cases which were repeated, within 3 days, 8 days, and 7 weeks, respectively.

The consistent trend towards normality seen in each of these cases suggests that single biopsy specimens provide reliable information about the degree of duodenal mucosal damage. Multiple biopsies, which were not considered justifiable in this study, would be required to exclude the possibility of patchy damage in the duodenum, and to ascertain the length of small intestine involved. Perhaps, as in coeliac disease, the severity and duration of symptoms are more closely related to the extent of intestinal injury rather than to the degree of change discernible in the duodenum. This may explain our finding that duodenal biopsy in the acute stage of gastroenteritis is of little help in management. Disaccharidase depression early in the illness does not predict which cases will develop persisting sugar intolerance. This complication seems to be age dependent, but the reasons for this association are unknown.

\section{Conclusion}

The first part of our working hypothesis, that considerable damage to the duodenal mucosa can occur in infantile gastroenteritis, has been confirmed. However, the second part, that persisting sugar intolerance is related to the degree of damage, has not been upheld.

We thank Dr. Ruth Bishop for microbiological studies, Rosa Kay who prepared the histological sections, and Max Murray who performed the disaccharidase assays. G.L.B. was supported by the Royal Children's Hospital Trainee Research Fellowship for 1971.

\section{REFERENCES}

Bohl, E. H., and Cross, R. F. (1971). Clinical and pathological differences in enteric infections in pigs caused by Escherichia coli and by transmissible gastroenteritis virus. Annals of the New York Academy of Sciences, 176, 150.

Bray, J. (1945). Isolation of antigenically homogeneous strains of Bact. coli neopolitanum from summer diarrhoea of infants. Fournal of Pathology and Bacteriology, 57, 239.

Burke, V., Kerry, K. R., and Anderson, C. M. (1965). The relationship of dietary lactose to refractory diarrhoea in infancy. Australian Paediatric fournal, 1, 147.

Collins, J. R. (1965). Small intestinal mucosal damage with villous atrophy. A review of the literature. American fournal of Clinical Pathology, 44, 36.

Dahlqvist, A. (1964). Method for assay of intestinal disaccharidases. Analytical Biochemistry, 7, 18.

Handforth, C. P., and Sorger, K. (1961). Failure of regeneration of small bowel mucosa following epidemic infantile gastroenteritis. Canadian Medical Association fournal, 84, 425.

Hirschhorn, N., and Molla, A. (1969). Reversible jejunal disaccharidase deficiency in cholera and other acute diarrheal diseases. Fohns Hopkins Medical fournal, 125, 291.

Kerry, K. R., and Anderson, C. M. (1964). A ward test for sugars in faeces. Lancet, $1,981$.

Maenza, R. M., Powell, D. W., Plotkin, G. R., Formal, S. B., Jervis, H. R. and Sprinz, H. (1970). Experimental diarrhea: Salmonella enterocolitis in the rat. Fournal of Infectious Diseases, 121, 475.

Partin, J. C., and Schubert, W. K. (1966). Precautionary note on the use of intestinal-biopsy capsule in infants and emaciated children. New England fournal of Medicine, 274, 94. 
Rho, Y. M., and Josephson, J. E. (1967). Epidemic enteropathogenic Escherichia coli, Newfoundland, 1963: autopsy study of 16 cases. Canadian Medical Association fournal, 96, 392.

Rosensweig, N. S., Dawkins, A. T., Jr., and Bayless, T. M. (1967). Lactase activity before and after acute febrile bacterial illness. Gastroenterology, $\mathbf{5 2}, 50$.

Toccalino, H., Licastro, R., Cardo, A. G., and Williams, M. (1971). Histologic changes in the small intestine in children with acute diarrhea. (Abst.) Fournal of Pediatrics, 78, 907.

Townley, R. R. W., Khaw, K. T., and Shwachman, H. (1965).
Quantitative assay of disaccharidase activities of small intestinal mucosal biopsy specimens in infancy and childhood. Pediatrics, 36, 911.

Walker-Smith, J. (1970). Transient gluten intolerance. Archives of Disease in Childhood, 45, 523.

Correspondence to Dr. R. R. W. Townley, Department of Gastroenterology, Royal Children's Hospital, Parkville, 3052, Victoria, Australia.

\section{British Association of Paediatric Nephrology}

At an informal gathering of a number of British paediatric nephrologists during the Dublin meeting of the European Society for Paediatric Nephrology in October 1972, it was felt that there was a need for the formation of a British Association of Paediatric Nephrology.

The objects of the Association are to promote the care of children with renal disease and to facilitate discussion of communal problems among its members. Membership of the Association will be open to those responsible for the care of children with renal disease.

The first scientific meeting of the Association will be held on 16 May at 10.00 a.m., at the Institute of Child Health, 30 Guilford Street, London W.C.1 (the Renal Association meets on the same day). Would those interested please contact Dr. T. M. Barratt, at the Institute of Child Health, 30 Guilford Street, London W.C.1. 